\title{
Research Support in Australian Academic Libraries: Services, Resources and Relationships
}

Gaby Haddow and Jayshree Mamtora

\begin{abstract}
In the last decade Australian academic libraries have increasingly aligned their research support services with assessment criteria used in the national research evaluation exercise (Excellence for Research in Australia). The same period has seen growing interest in research impact outside of traditional measures, such as bibliometrics. Social media has provided opportunities for research dissemination and new tools, altmetrics, to measure these activities have emerged.
\end{abstract}

This paper reports on research into the extent and nature of research support services at Australian academic libraries, how the services are managed, and the factors that influence their development and delivery. Quantitative and qualitative research methods were used to compare the findings with an earlier study and to provide a deeper understanding of research support in Australia. Three key themes services, staff and resourcing, and relationships - are discussed in relation to the management and challenges faced in providing research support.

\section{Introduction}

Research support services at Australian university libraries have tracked alongside the development of a research evaluation exercise; Excellence in Research for Australia (ERA). First trialled in 2010, the ERA is coordinated every three years by the Commonwealth Government and reports on research strengths across the Australian university sector. In its first draft, the proposed evaluation model used citations data to assess all research fields, however the implemented ERA uses citations for science fields only. The initial proposal increased the focus on bibliometrics and, more generally, the ERA intensified research as a priority at universities. With that came demands for improved research performance from academic staff. Although academic librarians had been aware of and sometimes used citations sources, the ERA raised that awareness and created an impetus for 
service development and research in the LIS field (Drummond \& Wartho, 2009; Haddow \& Genoni, 2009). An ERA round also involves extensive publications' data collection and verification, for which institutional repositories, managed by the library in most cases, have been pivotal.

More recently, altmetrics and research data management have entered the research arena. The interest in altmetrics has accelerated as researchers increasingly use social media to disseminate their research. Moreover, in Australia, as elsewhere, funding bodies are attempting to assess research by impact "beyond academia" (Australian Research Council, 2015; Stuart, 2015). Research data management is now a requirement by Australian research councils (National Health \& Medical Research Council, 2007) and it is an area to which academic libraries are contributing (Brown, Wolski, \& Richardson, 2015; Corrall, Kennan \& Afzal, 2013).

These changes are transforming the traditional academic librarian role to one of support for researchers at all stages of the research life cycle. With implications for staff skills, capacity, and service priorities, this study asked how Australian academic libraries are managing this extended role and what challenges they face in doing so.

\section{Background}

An early paper about research support (Hanson, 1995) forecast the potential for academic librarians to contribute to research evaluation activities. At the time there was a sense that libraries were reactive rather than proactive in delivering relevant services. In subsequent years, the literature has grown as research evaluation exercises have proliferated around the globe and librarians have reassessed their role in this new environment (see for example: Auckland, 2012; Bladek, 2014; Corrall, Kennan \& Afzal, 2013; Drummond \& Wartho, 2009; Haddow \& Genoni, 2009; Haddow, 2012; Petersohn, 2014).

Bibliometrics, in particular, has gathered increasing international attention in academic library literature over the last decade. Australians Drummond and Wartho (2009) described the bibliometrics-based Research Impact Measurement Service 
(RIMS), while in the United Kingdom (UK) Auckland (2012) identified bibliometrics knowledge as a means to support researchers in the future. Also in the UK, Haddow (2012) investigated bibliometrics as a component of research support at 'new' universities. An international study involving Australian, Irish, New Zealand and UK academic libraries explored bibliometrics services and skills, including constraints and training requirements (Corrall et al., 2013). From a United States (US) college library perspective, Bladek (2014, p. 332) noted "bibliometrics provides academic libraries with opportunities to apply their traditional expertise in a new context ... and contribute to forming a well-informed approach to research assessment at their institution". In Germany, Petersohn (2014) interviewed British and German librarians and information scientists about bibliometrics services, training, and relationships within an institution. Another international survey (Primary Research Group, 2016, p. 67 ) found that 80 per cent of the non-US participant libraries had experienced increased demand for bibliometrics services over the previous two years.

Some common themes - skills training and relationships - can be found in the literature. The need to provide staff with bibliometrics training is evident in the 'knowledge' Auckland (2012) identifies and in Haddow's (2012, p. 77) findings that "there are skill sets, such as bibliometrics ..., which are still under-developed ". For Petersohn's (2014, [p. 7]) participants “No formal training in bibliometrics was available to most ... so on- the -job training and self-education prevail" and Berrington (2015, p. 58) described the situation at Nottingham Trent University as "a very large degree of self- directed investigation, study and on-the-job learning". Taking a broader view, Bladek (2014, p. 341) makes the point that: “As research assessment gains importance, new methods, measures, and tools are constantly developed. It is crucial that the bibliometric-savvy librarian keep up with developments in the field". Related to training staff to perform different roles is the notion of confidence; a challenge noted by Corrall et al. (2013) and Blatchford et al. (2016, p. 37), who described these changes as "intimidating" for some staff.

A Research Information Network report (2010, p. 21) recommended libraries should work with their institution's research office to develop research support services. 
This relationship was later identified by Auckland (2012) and Haddow (2012) as an important factor in delivering research support services, and it is supported by Bladek (2014, p. 332) who stated: "As a result of our collaboration with the Provost's Office, we continue to be able to reach more faculty than we could alone".

Altmetrics has been described as providing "a fuller picture of how research products have influenced conversation, thought and behaviour" (Piwowar, 2013, p. 159). However, like bibliometrics, there are numerous issues in taking the metrics at face value. Cheung (2013, para 1) stated that altmetrics "lack the credibility as a performance measure", while Bornmann (2014) suggested they might complement, rather than replace, traditional metrics and the peer review process. Demonstrating the potential that altmetrics is perceived to have in supporting claims for research impact, Wolff, Rod and Schonfeld (2016, p. 100) commented on the increasing numbers of UK academics who are "adding non-academic audiences to those they seek to reach with their research". The author associated this with the UK's introduction of social impact as a criterion for research assessment.

As a relatively recent addition to the research metrics toolbox, much less is known about how libraries are using altmetrics. Corrall et al. (2013, p. 666) did not include altmetrics in their study, but predicted "the emergence of new measures and tools for research evaluation, reflecting the migration of scholarship to the web and the influence of social media". The Association of College \& Research Libraries (ACRL, 2014) biennial review highlighted altmetrics as one of the top trends, while a more recent survey of librarians in Oklahoma, found that, although less familiar with altmetrics than bibliometrics, the respondents were keen to upskill (Malone \& Burke 2016, p. 40). Support for Bornmann's view was found by an international study (Primary Research Group, 2016, p.78), in which the majority of respondents considered altmetrics to be 'adjunct' but 'subordinate' to bibliometric methods.

Research data management (RDM) has also made inroads in research support services in recent years. Auckland had identified RDM as a role for librarians in 2012 and Corrall et al.'s (2013) results showed 25.7 per cent of Australian respondents 
were providing advice on RDM. Like altmetrics, RDM was listed in the top trends by ACRL (2014) and Tenopir et al. (2013, p. 76) found "evidence that many ARL librarians believe they have the knowledge and skills" to provide RDM support in the future. Signalling that there are opportunities for librarians, UK researchers reported that RDM had increased in importance over the last few years (Wolff et al., 2016, p. 100).

Incorporating some of the points above, but particular to Australian academic libraries, Keller (2015, p. 75) provided an outsider's perspective on the most important aspects of research support; they included institutional repositories, bibliometrics and enhancement of research impact, and RDM. The author also commented on Australia's "more holistic approach" (p. 77) to supporting researchers while at the same time being left "to their own devices to define and develop suitable research impact services for their specific user group" (p. 78).

Our study was able to make some comparisons with Corrall et al.'s (2013) findings and we have also endeavoured to draw on the experiences and research results from the literature outside of Australia. By doing so, we hope to illustrate the nature of and challenges to the delivery of research support that will resonate with all academic libraries.

\section{Methods}

The first objective of this study was to investigate extent, resourcing and influencing factors in research support services in Australian university libraries. Some of our results could be compared with Corrall, et al.'s (2013) findings, which enabled us to identify changes over the intervening three years. Secondly, this study sought to gain a deeper understanding of research support service models and ethos at Australian university libraries and to determine factors that influence service provision. To achieve these objectives, we conducted a three-stage project that included a content analysis of Australian academic library websites, an online questionnaire and semi-structured interviews with research support librarians. The content analysis, reported in Mamtora and Haddow (2015), gathered quantitative evidence of the 
extent and types of research metrics being promoted by the libraries, the nature of supporting materials, and the use of research metrics in institutional repositories. It is the latter two stages that are the subject of this paper. The results of the questionnaire and interviews yielded specific information about research support services and rich insights into the environments in which they are provided.

A questionnaire distributed in 2012 by Corrall, et al. (2013) that focused on bibliometrics and RDM services was adapted, with the authors' consent, for this study. We retained the original questions about bibliometrics services, staff numbers, skills, training, relationships with other organisational units, and barriers to the development and delivery of research support services. Questions about altmetrics replaced the original questions about RDM (see Appendix 1). The semistructured interviews were designed to build on the questionnaire responses by gathering rich data about the libraries' research support model, ethos and factors that influenced how and how successfully their services were delivered (see Appendix 2).

All university librarians in Australia, with the exception of the university where Mamtora is employed (38 in total), were contacted in October 2015 seeking their consent for a staff member with research support responsibilities to participate in the study. The questionnaire was created in the survey software Qualtrics. Consent to participate in the questionnaire was gained on its first page and signed consent forms were collected from interviewees. The Curtin University Human Research Ethics Committee approved the research and Charles Darwin University provided approval on that basis.

Over 75 per cent (29) of the 38 Australian academic libraries completed the questionnaire and 13 agreed to a follow-up interview. Participating libraries were representative of the Australian university sector, for example, research-intensive, Australian Technology Network, and regional universities (see Australian Education Network http://www.australianuniversities.com.au/directory/australian-universitygroupings/). Skype or telephone interviews were offered to interviewees between 
December 2015 and January 2016, however a convenient time was not found for three librarians and they responded via email. The Skype and phone interviews ran for 30-45 minutes.

Qualtrics includes data analysis tools that were used to generate descriptive statistics for the quantitative data. These data were also transferred to spreadsheet software to compare the results with the 2013 study (Corrall, et al.) and to create figures. The interviews were recorded and transcribed to enable analysis using an iterative and systematic approach. Following Bradley's (1993, p. 445) advice, the analysis of the qualitative textual data involved "identifying meaningful units, grouping these together in categories, and developing relationships between categories". Repeated reading, reviewing and consideration of themes resulted in the identification of key issues raised in the interviews, which were contextualised within the unique circumstances and environments of the participating libraries.

\section{Results}

The results below are presented in three themes: Services, Staff and Resourcing, and Relationships. A final section discusses the future of research support services. The quantitative and qualitative results are reported within these themes to provide a richer understanding of the issues and relationships.

\section{Research Support Services}

Participants were provided with an overview of the study in the information sheet and before the interviews to define the data we aimed to collect. The study was described as exploring how libraries are supporting researchers with information and services relating to research impact measures, focusing on bibliometrics and altmetrics. The questionnaire gathered specific data about the two metrics and services, while the interviews took a broader approach and investigated aspects relating to research support more generally.

We compared the types of bibliometric services that were offered in 2015 against those reported in 2013 (data collected in 2012). Figure 1 below indicates that, from a 
reasonably high base, a slight increase has occurred during that time, with research impact calculations gaining most ground.

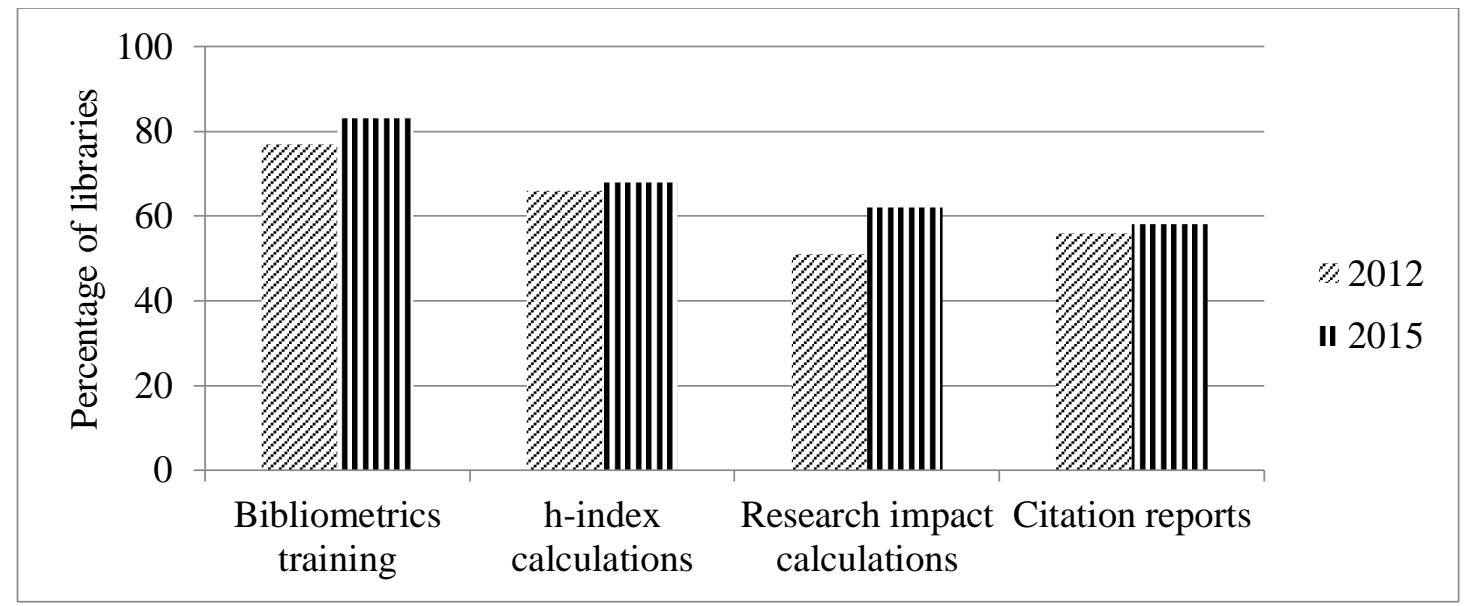

Figure 1: Percentage of libraries offering bibliometric services in $2012(n=35)$ and 2015 $(n=29)$

Data from the questionnaire and interviews about research support showed that these services were most often provided to assist with grant applications, promotions, appointments, and publishing. However, the service models varied greatly. Three libraries were struggling to engage their academic community, either from lack of interest by researchers or due to resourcing challenges. Most of the libraries had developed a service model, ranging from the highly structured "very programmed research bibliometrics service" to a less formalised, but equally wideranging service that aimed at "capacity building ... we work with researchers and train researchers to use the tools and be able to do their own bibliometric work". Only two of the interviewees indicated that research support was not a priority, or emerging as one, for their library due to resourcing and conflicting demands.

Training sessions for researchers, as workshops or individual consultations, was the most frequently offered research support service. Some libraries generated sophisticated reports that enabled academics to track their research impact. In three cases a more strategic level of support was provided, such as for senior management decisions about establishing research centres. Three libraries offered services 
designed to enhance research impact by assisting researchers to establish profiles on social platforms (for example ResearchGate).

Since 2012, altmetrics has become more widely known and we explored whether the libraries had introduced related services. The questionnaire results showed that less than half were delivering altmetrics training and about a third were providing altmetrics reports. The lower level of service provision in altmetrics, compared with bibliometrics, was reflected in the interviews. Most libraries (70 per cent) had either included altmetrics tools in their institutional repository, had considered subscribing to altmetrics tools or were aware of researcher interest. However, as one librarian stated, altmetrics services were being introduced "in small ways".

In the questionnaire, participants were asked to note from a fixed response list what bibliometrics and altmetrics tools were subscribed to and/or supported by their library. As shown in Figure 2, bibliometric sources dominate in the findings, including Google Scholar, which provides citations data and metrics based on citations. With the exception of Altmetric.com, very few of the libraries subscribe to and/or support altmetrics tools

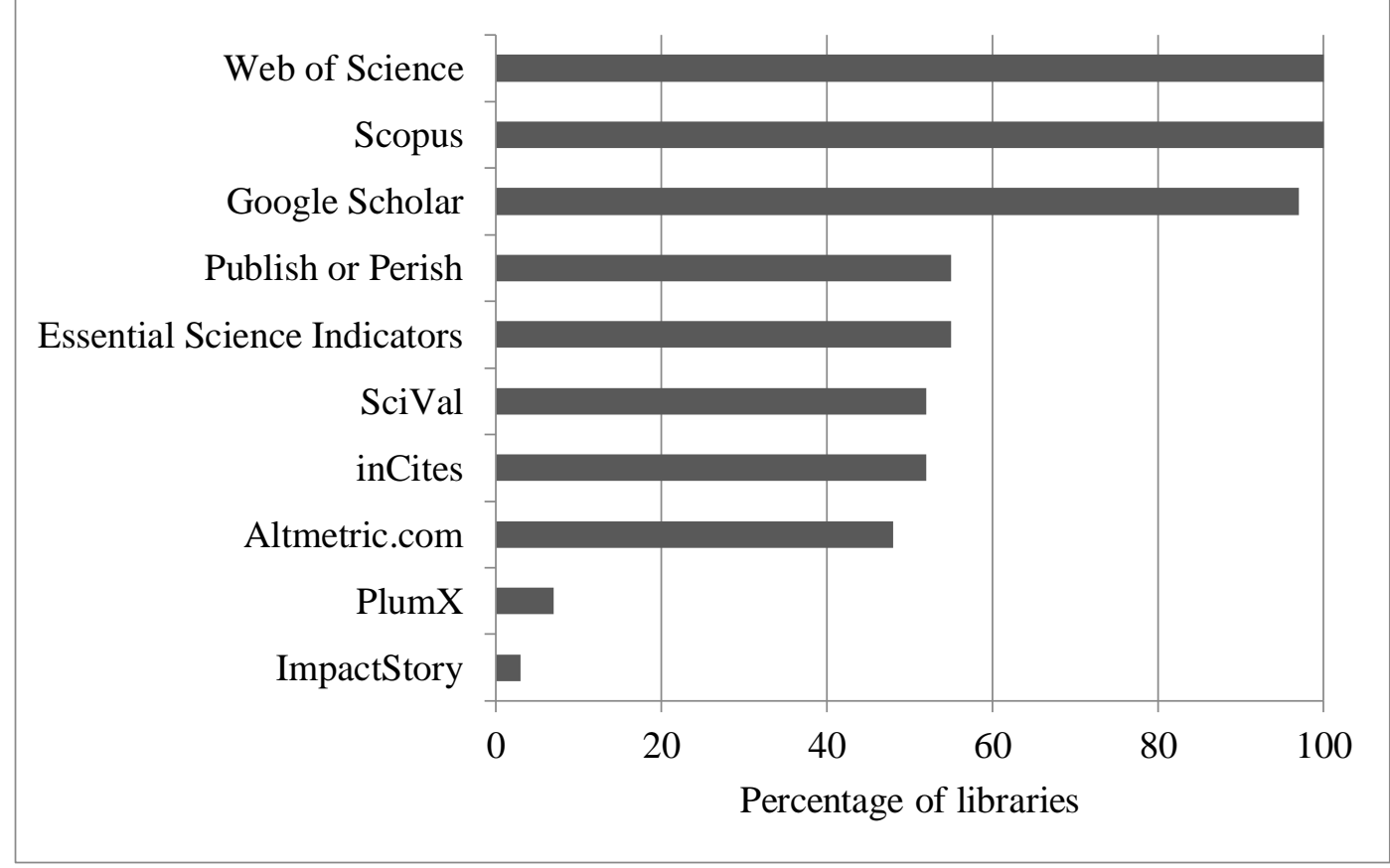

Figure 2. Bibliometric and altmetric tools subscribed to and/or supported $(n=29)$ 
Corrall, et al. (2013, p. 655) reported that just over a quarter of their responding libraries were offering services related to research data. Although our questionnaire did not include questions about RDM, four interviewees (just under a third) mentioned they were responsible for RDM support and another six were considering or planning RDM services.

Researcher demand and awareness of research support services was an important factor in both the level and type of service. Some interviewees mentioned low researcher interest, while others indicated they were yet to develop a service model or having difficulties resourcing the service. The level of research support by libraries did not appear to be associated with its parent organisation's research tradition. That is, the libraries with less developed services were from both research-intensive and teaching-focused universities.

Over half of the questionnaire participants noted that their library was experiencing increased demand and five interviewees mentioned high or increasing demand for the services; attributing it to their university's stronger focus on research and academic performance. The results suggest that increased demand was associated with services relating to metrics for benchmarking, researcher profiles and research impact assistance, as well as training and standard bibliometric calculations. A few interviewees were clearly frustrated by a lack of awareness of what the library could provide. For example, one librarian commented that after a library presentation about research support to over 40 researchers there was "not a single request for $a$ report". Other factors that influenced the delivery of services, such as resourcing and relationships, are discussed below.

\section{Staff and Resourcing}

Delivering library services of any kind is highly dependent on staff resources, both numbers and skills. Questions about staffing, skills and training were included in the study by Corrall, et al. (2013) and our research followed up with the same questions to identify any changes over the three years. 
In 2012 less than a third of the participants had the term 'research' in their title, compared with two-thirds in 2015. Although several interviewees indicated that research impact services had not been developed in their library, in most of these cases liaison librarians were responsible for the service in an informal capacity. This explains the questionnaire results for staff numbers involved in providing bibliometric and altmetrics services; no libraries had fewer than 2-5 staff involved in the services, 14 libraries had 6-10 staff, and four libraries had more than 15 staff involved in the services. The staffing structures varied from an ad hoc service provided by liaison librarians to dedicated teams and units.

We were able to compare staff training in research metrics, as well as constraints to providing the services, with the earlier study's findings. The question from the 2012 survey was amended to read 'bibliometrics and/or altmetrics' in our study, rather than 'bibliometrics' only. Minor differences were evident in the findings for staff training over the three years, with a slightly higher proportion of staff learning onthe-job and being self-trained.

Constraints to providing the services drew a high 'other' response in the 2015 questionnaire and these are discussed below. The highest fixed responses from 2015 are presented alongside the $\mathbf{2 0 1 2}$ data in Figure 3. There has been a marked change over the three years that shows that constraints relating to staff skills and confidence have decreased by almost a half. However, a larger proportion of respondents reported that the service was not perceived as a library role in 2015. 


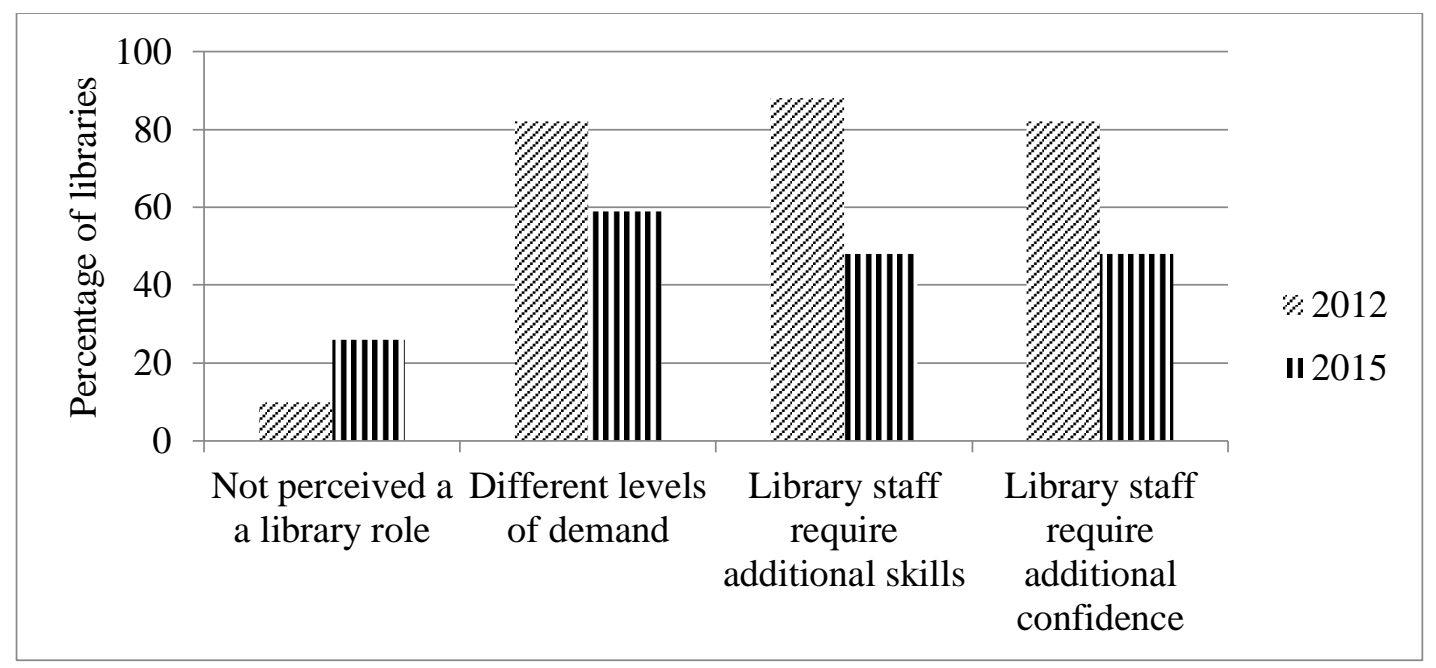

Figure 3. Factors that constrain the development of bibliometric and altmetrics services in $2012(n=35)$ and $2015(n=27)$

Although staff skills had become less of a constraint by 2015 , the interview data suggested it remained a challenge. More than two-thirds of the interviewees discussed issues relating to lack of staff skills and the need for training. Two interviewees said they didn't actively promote a research support service due to staffing, while others associated skills and training with the rapid changes in the research impact tools available and the need for constant up-skilling. Very few of the libraries employed staff with specialist skills and one interviewee noted "the background of librarians doesn't always lend itself to providing information that really requires fairly sophisticated mathematical understanding".

The importance of on-the-job training was also borne out in the interviews. In one case, staff had been sent away for training and in another a librarian with expertise was invited to visit to deliver training. Several libraries had a few skilled staff and they were responsible for training their colleagues, demonstrated in the comment: "[one librarian] has been putting a substantial amount of work into developing capacity".

Staff who are confident delivering research support services appears to have improved, or at least was not regarded as a constraint to the same extent as it was in 2012. However, a number of the interviewees noted that staff felt challenged by the 
skills needed to deliver research support services and this merged into staff attitudes. The interviewees discussed these challenges in terms such as "getting the staff to come with us", "not looking to do different things" and "a certain amount of fear associated with change".

Even with expert and confident staff, the questionnaire and interview responses indicate that capacity, in terms of staff numbers and time, is a challenge. As noted above, over half of the questionnaire participants reported demand for research support services was increasing and five of the interviewees indicated funding was an issue. Interviewees' concerns about capacity are illustrated in the comments: "fear of being inundated", "added onto what the [liaison] librarians already do", and "it's too labour intensive". Funding for products that generated research metrics was also a factor for a number of libraries; to the extent that one library had cancelled their subscription to an important citation database.

A notable result was the high level of interviewee awareness of the research environment at their university, nationally and internationally. The comments of ten interviewees indicated a deep understanding of the importance of research metrics and impact to researchers and their institution. This knowledge related not only to the current research environment, but extended to plans for research assessment in the future. For example: "I imagine Australia will follow in the steps of the REF in the UK", "the mooted changes to the way block grant funding is going to be distributed ... and the way the ERA might work", and "complicated implications because they're talking about measuring engagement". It was also evident in interviewees' discussion about RDM (a number of the libraries were taking the initiative in their university) and in exasperation that more was not being done to stimulate research at their university.

The interviewees' knowledge encompassed the uses (or misuses) of metrics and tools for different disciplinary groups, as well as the importance of contextualising the data generated by both bibliometric and altmetrics tools. This is illustrated in comments such as: "the difficulty is that without a very sophisticated user the data is 
potentially quite meaningless" and "in our [Humanities Arts and Social Sciences] area

- the $h$-index is kind of meaningless". One interviewee especially singled out the altmetrics tools, saying: "we do have to be pretty careful about how they are used. And they don't go hand in hand either as a true measure of social impact or as a measure of quality".

\section{Relationships}

Data about partnerships within the university were gathered in the questionnaire and interviews. Questionnaire respondents were asked if the library worked with other organisational units to deliver research metrics services. In the study by Corrall et al. (2013, p. 653), 54.3 per cent of the responding libraries partnered with the university's research office or equivalent. Three years later this number had increased to 78 per cent $(n=14)$.

Relationships with the research office were also explored in the interviews. They ranged from virtually non-existent to close collaboration in the provision of research support services. At the positive end of the scale, one interviewee stated "we haven't had to sell ourselves to the [research office]", but another interviewee expressed disappointment that more partnering had not occurred: "we have been struggling for some years to have collaborative relationships". Overall, the majority of the relationships appeared to be strong and some were true partnerships in research support initiatives. Collaborative research support services included: joint training sessions for new researchers and graduate students; large grant application activities; presentations to senior management; acquisition and implementation of relevant IT systems; and membership of research committees. The success or otherwise of these relationships appeared to be associated with a university's research culture and strategy. That is, the universities with a less developed research culture or lacking a clear research strategy were those where the relationship between the library and research office were not as strong.

All of the questionnaire respondents $(n=29)$ indicated their library was responsible for the university's institutional repository or a publications database. This role 
means that, as six interviewees noted, the library provides critical support during an ERA round in the form of collecting and verifying publications information.

Liaison librarians also play a key role in developing research support relationships with individuals and groups. The role varied across the libraries, being discussed in terms such as "offered ... on an informal level", "do the research support work", and "prime purpose ... is to support the academic and the research activities of the university".

In the course of the interviews, another relationship emerged and that is networking and sharing between academic librarians. Two libraries had called on expertise from elsewhere to help train staff in research metrics and three interviewees made comments that indicated they were aware of what other libraries were doing in the area. In addition, an annual research support event (since 2013) was mentioned with enthusiasm by four interviewees as an opportunity to learn from and share ideas with colleagues.

\section{The Future in Research Support Services}

Finally, we asked interviewees about what they thought the future held for research support services. Efficient use of resources was a key issue for a number of libraries, including those that were yet to decide on a fully developed research support service. This was expressed in comments such as: "identify a service that is sustainable for us to deliver given our staffing", "we are looking into producing more online tutorials so that we can utilise staff time more effectively", "can't believe we can't automate all this bibliometric stuff", and "have more in-line metrics in our repository ... to save time".

Research impact assessment was raised as a challenge by six interviewees. The inclusion of research impact in future ERA rounds follows the UK's introduction of this new measure of quality and the interviewees were aware of its implications. Their comments demonstrate not only knowledge of the national and international research environment, but also their strategic approach to providing research 
support services, for example in: "more acceptance and credibility ... of alternative metrics", "expect to get more of that [societal impact]", and "how can we assist with that broader measurement of research impact". The interviewees also mentioned the challenges of working with research metrics tools generally, commenting with "metric stuff is only going to get more difficult and probably more complicated", "we might end up with a much more standardised set of metrics", and "better tools and metrics to tell the story".

\section{Discussion and Implications for Practice}

Two words define research support services as they currently exist in Australia: 'potential' and 'opportunity'. The former is evident in the increased demand for support by researchers and librarians' awareness of relevant services. Opportunity is demonstrated in the relationships libraries have established within universities and the services that are successfully implemented. The transition from potential to opportunity is influenced by a number of factors, some of which are beyond the libraries' control. Most important among the influencing factors are the research environment and staff capacity.

The research environment has a significant impact on research activity and library engagement at institutional and individual levels. It can create opportunities and challenges for the delivery of research support. Overall, research metrics services and staff with research support responsibilities have increased over the last three years and it appears the national research environment is behind this growth. The librarians demonstrated high awareness of measures that are useful to researchers across different disciplines and the need for strong research performance. Recent international literature about the role of academic librarians reflects this same awareness of the research environment and metrics (Blatchford, 2016; Malone \& Burke, 2016; Primary Research Group, 2016).

While bibliometrics are still the primary research metric included in research support services, altmetrics are attracting increased attention due to the introduction of impact outside academia as an evaluation criterion. This has parallels with the UK 
research environment (Research Excellence Framework, 2014; Stuart, 2015), where impact has already been tested. Australian academic libraries have recognised the opportunity by including altmetrics tools in their institutional repositories and in information about altmetrics in their webpages (Mamtora \& Haddow, 2015), but altmetrics services are somewhat in limbo. In part this is due to the uncertainty around what the metrics actually mean and it also relates to librarians' lack of knowledge (Malone \& Burke, 2016). Presumably, the very few altmetrics tools that are subscribed to or supported by libraries is associated with these issues. It is an area that has a great deal of potential for research support services, if more clarity around the metrics was achieved and staff were adequately trained. Also hovering between potential and opportunity is RDM. Most libraries are considering, if not already involved in, RDM services that will help their institution address funding agencies' requirements (National Health \& Medical Research Council, 2007) and researcher interest (Wolff et al., 2016). However, as a nascent research activity, it is too early to predict what type and level of RDM service academic libraries will deliver in the future.

While some libraries have created opportunities to establish research metrics services, a lesser number are hamstrung by their institution's research environment. These librarians can see the potential, but are thwarted by a lack of interest from researchers and/or low levels of engagement with their research office. The higher proportion of responses in our study, compared with Corrall et al. (2013), reporting research metrics was not perceived as a library role is concerning. A possible explanation is the importance of these metrics to institutions seeking to improve their research performance. If we were to accept this thesis, the relationship with the research office as well as the wider academic community is critical. However, despite the efforts of some libraries to develop relationships it was evident that a bigger and uncontrollable issue was at play - the institution's research environment. For these libraries it is hoped that a library champion will emerge and appreciate their potential contribution. 
Staff capacity, both skills and numbers, is a major challenge to libraries in realising their potential to provide research support services. Although constraints relating to staff skills and confidence have decreased since Corrall et al. (2013) collected data, training to develop Australian library staff expertise remains an issue, as it is elsewhere (Berrington, 2015; Bladek, 2014; Haddow, 2012; Petersohn, 2014). One interviewee made a comment that encompasses the problem, which is that librarians' are rarely equipped with the types of skills required for working with the complex research metrics that exist today. These specialist skills are generally learned on-the-job from peers and are heavily dependent upon expertise already residing within a library. It is not enough, however, to rely on existing skills in an environment in which new and more sophisticated research metrics tools are being released regularly. Providing effective research support in this environment requires a proactive approach to ongoing training.

Competing priorities and staff that are working to capacity means that the opportunity for delivering research support is limited in some cases. The recent additions, altmetrics and RDM, to the suite of services that might be offered in research support are likely to create a further burden on skills training and staff workloads. On a more positive note, many of the librarians interviewed talked about their opportunity for networking and sharing ideas about research support with other libraries and librarians. However, a reality for a few libraries is that a change in staff attitudes is required before the library can fully act on the potential that exists in their institution.

As Keller (2015) observed, Australian academic libraries have a great deal of autonomy in how they design and provide research support services. The service models operating range from research support delivered by liaison librarians as it arises, to highly structured models that have been designed by the library to meet specific research support needs. This can be viewed as an opportunity for Australian academic libraries and a good number have seized it successfully. 


\section{Conclusion and implications for practice}

The empirical evidence presented in this paper has indicated strengths and challenges that influence the potential for academic libraries to deliver effective and valued research support services. The potential lies in their access to and engagement with research support tools and their academic community. To realise this potential, however, there are several significant challenges to overcome.

The following points act as a guide for academic libraries to create opportunities and make a strong contribution to the research environment at their institution in the provision of research support services:

- Research metrics are likely to become more complex and sophisticated and academic libraries need staff that are skilled in working with them;

- Professional development in research metrics will provide academic librarians with an improved understanding and skills;

- Building collaborative relationships with the institution's research office will increase the potential for an academic library to engage more effectively with its research community; and

- Sound knowledge of the research environment enables academic libraries to develop and deliver the most relevant services.

\section{References}

Association of College \& Research Libraries (ACRL) (2014). Top trends in academic libraries: A review of the trends and issues affecting academic libraries in higher education. College \& Research Libraries News, 75(6), 294-302.

Auckland, M. (2012). Re-skilling for Research: An Investigation into the Role and Skills of Subject and Liaison Librarians Required to Effectively Support the Evolving Information Needs of Researchers. Report commissioned by Research Libraries UK. http://www.rluk.ac.uk/wp-content/uploads/2014/02/RLUK-Re-skilling.pdf Australian Research Council. (2015). Research Impact Principles and Framework. http://www.arc.gov.au/research-impact-principles-and-framework 
Berrington, M. (2015). Supporting academic librarians' transition from generic to research dedicated roles. In R. Raju, A. Adam, G. Johnson, C. Miller \& J. Pietersen (Eds), The Quest for Deeper Meaning of Research Support (pp. 5360). Cape Town: University of Cape Town Libraries. http://www.openbooks.uct.ac.za/arl/index.php/uctlibraries/catalog/download $/ 17 / 15 / 146-3$

Bladek, M. (2014). Bibliometrics services and the academic library: Meeting the emerging needs of the campus community. College \& Undergraduate Libraries, 21(3/3), 330-344.

Blatchford, B., Borwick, C., Glen, S., Hall, B., Harding, A., Hilliar M.A., \& Oakley, S. (2016). Librarians supporting research in Wales: Collaborative staff development and capacity building. SCONUL Focus 67, 37-42. http://www.sconul.ac.uk/sites/default/files/documents/8 20.pdf

Bornmann, L. (2014). Do altmetrics point to the broader impact of research? An overview of benefits and disadvantages of altmetrics. Journal of Informetrics, 8(4), 895-903.

Bradley, J. (1993). Methodological issues and practices in qualitative research. The Library Quarterly, 63(4), 431-449.

Brown, R. A., Wolski, M., \& Richardson, J. (2015). Developing new skills for research support librarians. The Australian Library Journal 64(3), 224-234.

Cheung, M. K. (2013). Altmetrics: Too soon for use in assessment. Nature, 494(7436), 176-176.

Corrall, S., Kennan, M. \& Afzal, W. (2013). Bibliometrics and research data management services: Emerging trends in library support for research. Library Trends, 61(3), 636-674.

Drummond, R. \& Wartho, R. (2009). RIMS: The Research Impact Measurement Service at the University of New South Wales, Australian Academic \& Research Libraries, 40(2), 76-87.

Haddow, G. \& Genoni, P. (2009). Australian education journals: Quantitative and qualitative indicators. Australian Academic \& Research Libraries, 40(2), 88-104. 
Haddow, G. (2012). Research support in a research assessment environment: The experience of 'new' universities. Library and Information Research, 36(113), 63-73.

Hanson, T. (1995). The role of academic libraries in supporting research. The New Review of Information and Library Research, 1, 197-206.

Keller, A. (2015). Research support in Australian university libraries: An outsider view. Australian Academic \& Research Libraries, 46(2), 73-85.

Malone, T. \& S. Burke (2016). Academic librarians' knowledge of bibliometrics and altmetrics. Evidence Based Library and Information Practice 11(3): 34-49.

Mamtora, J. \& Haddow, G. (2015). Australian academic libraries and research support. In R. Raju, A. Adam, G. Johnson, C. Miller \& J. Pietersen (Eds), The Quest for Deeper Meaning of Research Support (pp. 80-89). Cape Town: University of Cape Town Libraries.

http://www.openbooks.uct.ac.za/arl/index.php/uctlibraries/catalog/download $/ 17 / 15 / 146-3$

National Health \& Medical Research Council (2007). Australian Code for the Responsible Conduct of Research. https://www.nhmrc.gov.au/guidelinespublications/r39

Petersohn, S. (2014). Bibliometric services in research evaluation: A new task area strengthening the jurisdiction of academic librarians. Proceedings of the IATUL Conferences, http://docs.lib.purdue.edu/iatul/2014/performance/1

Piwowar, H. (2013). Value all research products. Nature, 493, 159.

Primary Research Group (2016). International Benchmarks for Academic Library Use of Bibliometrics and Altmetrics, 2016-17. Primary Research Group. Research Excellence Framework (2014). REF2014. http://www.ref.ac.uk Research Information Network (2010). Research Support Services in UK Universities. London: Research Information Network.

Stuart, D. (2015). Finding "good enough" metrics for the UK's Research Excellence Framework. Online Information Review, 39(2), 265-269.

Tenopir, C., Sandusky, R.J., Allard, S. \& Birch, B. (2013). Academic librarians and research data services: Preparation and attitude. IFLA Journal, 39(1), 70-78. 
Wolff, C., Rod, A.B., \& Schonfeld, R.C. (2016). UK Survey of Academics 2015. Ithaka S+R, Jisc, RLUK. http://www.sr.ithaka.org/publications/uk-survey-ofacademics-2015/ 